\title{
Balkanologie
}

Balkanologie Revue d'études pluridisciplinaires

Vol. VIII, $n^{\circ} 2$ | 2004

Volume VIII Numéro 2

\section{de Hongrie (Georges), Des Turcs. Traité sur les mœurs, les coutumes et la perfidie des Turcs}

Toulouse : Anachasis, 2003, 222 p.

\section{Bernard Lory}

\section{CpenEdition}

\section{Journals}

Édition électronique

URL : http://journals.openedition.org/balkanologie/2037

DOI : 10.4000/balkanologie.2037

ISSN : 1965-0582

Éditeur

Association française d'études sur les Balkans (Afebalk)

Édition imprimée

Date de publication : 1 décembre 2004

ISSN : 1279-7952

\section{Référence électronique}

Bernard Lory, « de Hongrie (Georges), Des Turcs. Traité sur les mœurs, les coutumes et la perfidie des

Turcs », Balkanologie [En ligne], Vol. VIII, n 2 | 2004, mis en ligne le 20 janvier 2010, consulté le 17 décembre 2020. URL : http://journals.openedition.org/balkanologie/2037 ; DOI : https://doi.org/ 10.4000/balkanologie.2037

Ce document a été généré automatiquement le 17 décembre 2020.

(C) Tous droits réservés 


\section{de Hongrie (Georges), Des Turcs. Traité sur les mœurs, les coutumes et la perfidie des Turcs}

Toulouse : Anachasis, 2003, 222 p.

\section{Bernard Lory}

\section{RÉFÉRENCE}

de Hongrie (Georges), Des Turcs. Traité sur les mours, les coutumes et la perfidie des Turcs, Toulouse : Anachasis, 2003, $222 \mathrm{p}$.

1 Il faut saluer la traduction en français du Tractatus de moribus, condicionibus et iniqui-tia Turcorum, réalisée par Joël Schnapp. Rédigé à la fin du règne de Mehmed II, ce petit livre connut les honneurs de l'imprimerie en 1481. Son intérêt scientifique n'avait pas échappé aux chercheurs avertis, comme Hasluck, mais il restait inaccessible au commun des mortels. Le mérite de son exhumation revient à l'Allemand Klockow, qui en a publié une édition critique en 1993. L'édition française propose une introduction d'une douzaine de pages par le traducteur, et une postface du même volume due à Michel Balivet ; un nombre restreint de notes de bas de page éclaire les aspects les plus obscurs. C'est donc une édition "légère ", censée ne pas effaroucher le lecteur par trop d'érudition. Nous ne sommes pas convaincus que cette formule soit la plus heureuse. On ne rentre pas facilement dans un texte du quinzième siècle. Quant à tenter l'aventure, le lecteur ne refuserait pas un peu d'aide supplémentaire.

2 L'aventure le mérite bien pourtant! George de Hongrie, qui était en fait un Saxon de Transylvanie, fut capturé par les Turcs en 1438 à Sebes et ne fut libéré que 20 ans plus tard en 1458. C'est donc un contemporain du « janissaire » serbe Konstantin Mihajlović d'Ostrovica (qui fut captif de 1455 à 1463), mais leurs deux ouvrages, et les deux personnalités qui se révèlent entre les lignes, sont fort différents. Le «janissaire » consacre la majeure partie de son ouvrage à l'histoire et à l'organisation de l'Empire 
ottoman, ne laissant à la religion qu'une place secondaire ; ce fut avant tout un homme d'action et, par son écrit, nous pouvons rentrer dans la mentalité d'un combattant ordinaire de l'armée de Mehmed le Conquérant. Georges de Hongrie ne connut aucune aventure militaire exaltante, car il fut esclave et les souffrances qu'il endura le marquèrent de façon indélébile. Son interrogation religieuse porte sur la volonté de Dieu, qui a permis ces souffrances et qui permet à «la secte des Turcs» de progresser impunément. Le millénarisme de Joachim de Flore lui fournit un cadre explicatif.

Mais 20 ans de cohabitation avec l'Autre sont une expérience dont on ne sort pas indemne: plus Georges de Hongrie dénonce la perfidie des Turcs, plus il est obligé d'admettre leurs qualités militaires (discipline, endurance), leur simplicité de vie et l'absence de préjugés de naissance, la modestie de leurs femmes, la piété et les miracles de leurs saints. Tout cela est bien sûr diabolique, et il entre dans des développements théologiques assez indigestes pour tenter de sortir de ses contradictions. Plus le lecteur avance dans sa lecture, plus il est pris sous le charme de ce discours schizoïde, cette haine-amour portée aux Turcs et à leur foi, et plus s'ancre en lui la conviction que Georges de Hongrie est "passé de l'autre côté ». Celui-ci s'en défend, bien entendu (les époux Bennassar ont montré dans Les chrétiens d'Allah les démêlés fatals des renégats avec l'Inquisition au $\mathrm{XVI}^{\mathrm{e}}$ siècle), mais il montre des connaissances suspectes en matière de dervicherie et avoue même connaître de nombreux hymnes soufis par cœur, talent qui lui aurait valu une certaine considération en Turquie. Cette ambiguïté du discours de Georges de Hongrie fait tout l'intérêt de son témoignage. Il nous montre qu'au XVe siècle, l'altérité religieuse a parfois des lignes de démarcation brouillées. La domination ottomane a pu susciter l'adhésion active d'une partie de la population balkanique. Nous connaissons mal les mentalités de cette époque. Georges de Hongrie nous fait ressentir la sidération des chrétiens face aux attaques-éclairs des akinci, la déréliction de l'esclave vendu à l'encan, la difficulté à parler de l'Islam avec un vocabulaire chrétien (églises, prêtres, religieux pour désigner mosquées, ulema, derviches), les craintes du pouvoir envers les courants hétérodoxes mal contrôlés... Ayant laissé une partie de sa vie, et peut-être de ses espérances, de l'autre côté, il nous sort de toute approche binaire en matière d'altérité.

4 Un dernier point de balkanologie. Au chapitre VIII, Georges de Hongrie cite cinq royaumes « du nord » qui font preuve de complaisances coupables envers les Turcs et ne freinent pas leur expansion : «la Bosnie, l'Arnaut, le Laz, la Slavonie et l'Albanie». Nous pensons que Joel Schnapp identifie correctement le Laz avec la Serbie, mais ce nom n'a vraisemblablement rien à voir avec un prince Lazar (ni Hrebeljanović, mort depuis longtemps, ni Branković, éphémère et contesté) ; c'est plus probablement une déformation de Ras, Rascie. Le doublon Arnaut / Albanie a aussi son intérêt, le premier terme désignant sans doute l'Albanie du sud (le Sancak-i Arvanit) sous administration ottomane directe, le second les territoires du nord défendus par Skanderbeg, ou ce qu'il en restait après sa mort en 1468. 